\title{
Research into University and College Library Resource Construction under the Big Data Background
}

\author{
Xinyu Wang \\ library, \\ JiLin Agricultural University, \\ Changchun, China \\ Email: 729738677@qq.com
}

\author{
Qingsong Zhang \\ library, \\ JiLin Agricultural University, \\ Changchun, China \\ Email: 1007738301@qq.com
}

\begin{abstract}
With the continuous deepening of the information age, university libraries play a decisive role in education, so the library resources construction is particularly important. This article intends to start from the two aspects: the construction of digital information and its sharing and co-construction. It focuses on the construction of university library resources, deeply analyze its important role in university library construction, so as to better promote the construction of library collection resources of university library, and the rapid development of colleges and universities.
\end{abstract}

\section{Keywords-university libraries; library resources; construction; strategy}

\section{INTRODUCTION}

In recent years, with the continuous development information technology, the library has accumulated large numbers of digital resources and covered the knowledge of science and society. But as the information resources rapidly increased, overlapping contents of redundant information also increases sharply, which reduces the efficiency and quality of users access to information and affects users on the use of the library information resources. For a series of problems of library collection information exist in the process of resource utilization, in order to further develop and make full use of collection resources, to provide targeted and in-depth knowledge service system for all types of users, we need to study people demand related relationship among the library collection resources and aggregate them, to meet high quality requirement of library collection resources service for people.

\section{MAJOR PROBLEMS WITH LIBRARY RESOURCE AND SERVICE CONSTRUCTION}

\section{A. Relatively slow library resource update speed}

Generally speaking, university and college libraries will regularly purchase resources according to certain plan. However, with the passage of time, libraries are filled with more and more books. This, on the one hand, contributes to the richness of library resources; on the other hand, leads to the increase of some old-fashioned resources, such as newspapers and journals with high effectiveness. As time goes on and the scientific research moves ahead, the past findings have been continuously updated, replaced or even overturned. Knowledge of such kind does not have high use value. The amount of capitals, that each university and college use for purchase, differs. Those with inadequate capitals or less financial support might be slow in updating their resources ${ }^{[1]}$.

\section{B. Relatively limited supply forms of library resources}

From the perspective of supply types, most university and college libraries mainly provide print resources. However, with the popularity of the communication tools and electronic books and the changes of reading habits, more and more university and college teachers and students are not just satisfied with print resources. To the post-90's who are open to novel things, they hope they can acquire knowledge through electronic communication devices. From the perspective of supply models, lending or printing dominates. Some electronic reading room can provide download service. From the perspective of transmission direction, most resources are sent from libraries to teachers and students. The one-way transmission is obviously not beneficial for the interaction between librarians and readers. From the perspective of supply resources, part from providing teachers and students with the free account to download resources from the online databases, including China Periodical Database and CNKI, libraries mainly rely on self-supply. The resource sharing between them and the provincial and municipal libraries or libraries of other universities and colleges is limited. This, to some extent, narrows the scope of resource supply.

\section{Relatively weak service awareness of librarians}

Most people, including university and college students and teachers and even librarians themselves, regard library management as a relaxing job requiring no techniques and confine it to book collection, information registration and data entry. The superficial and even misleading idea greatly influence and suppress the working enthusiasm of librarians. As a result, university and college librarians have a weak service awareness.

\section{Relatively limited service modes of librarians}

University and college libraries serve students and teachers through relatively limited service modes. Currently speaking, there are two service modes. First, retrieval assistance. When teachers and students cannot find certain resource they need, librarians can search the location and status of the resource for them through their search system. 
Second, formality handling. Librarians are expected to handle formalities, including borrowing, checking and returning. On the whole, the service modes are limited and dull. Teachers and students have no access to more human-oriented and diversified service modes ${ }^{[2]}$.

\section{STRATEGIES FOR UNIVERSITY AND COLLEGE LIBRARY RESOURCE CONSTRUCTION}

Targeted at the prominent problems with the university and college library resource construction, this paper puts forward the relevant construction strategies in accordance with the generation principles and the development trend of university and college library resource construction.

\section{A. Adjust the library resource structure}

on one hand, the resource aggregation in-depth perform on the horizontal through many means of polymerization from a broader range of the associated information together, which reflects the breadth of information resource aggregation, on the other hand, it aggregates large numbers of information resources to achieve more meaningful and valuable from a deeper level, by professional way and method to collect information resources in deep searching and explore the substantially relationship between information resources. In order to realize the resource more meaningful and valuable together to information users, we need comprehensively using polymerization means based on the cooperation, content,citation relations,making all kinds of information together to form a large dense network of collection information.

In terms of resource structure adjustment, university and college libraries should do a good job in the following aspects: 1) Increase the purchase percentage of digital resources: University and college libraries shall pay more attention to digital resources, because digital resources are low in cost, small in occupation, large in volume and convenient to use. From the future development trend of library resources, digitalization is an inevitable trend. Therefore, in terms of budgeting, university and college libraries should increase budgeting for digital resources and increase the percentage of digital resources. 2) Increase the percentage of social sciences resources. The goal of universities and colleges is to bring up talents with political integrity and professional competence. Social sciences resources play an important role in students' moral education. Since the percentage of these resources is low, efforts should be intensified to increase the percentage. 3) Increase the percentage of the foreign literatures. At present, the latest research findings are published in foreign language. The increased percentage of foreign literatures can contribute to the internationalization of university and college teaching scientific research ${ }^{[3]}$.

The collection is the foundation on which a library's function is performed and its service benefit realized. Within the context of the digital environment, the format and the media of the information resources, users' needs, and the operation patterns of libraries are undergoing changes. Traditional selection criteria of print resources are no longer suitable for the selection of digital resources. Developing a study on selection criteria of digital resources will be beneficial not only to the promotion of a scientific and standard selection process, but also to the maximization of the allocation of library resources. Further more, it will improve the effectiveness and efficiency of the development of digital resources collection. Therefore, it will eventually support and guarantee libraries to innovate their service models, expand their development space and realize their sustainable development. Researches on the selection criteria of digital resources have been the concern of library circles both at home and abroad.

\section{B. Introduce the scientific decision-making mechanism for resource purchase}

The priority of library resource construction is the resource purchase decision-making, namely what and how many resources to buy. Only after the two questions are clarified can the purchase be conducted. In order to ensure the purchase of ideal library resources, university and college libraries should optimize their purchase decision-making mechanism. They should take readers' demands consideration by visiting the subject leaders, department leaders, lecturers and students. The demands of all these target readers should be reflected in the resource purchase decision-making mechanism. Most users of the library resources are the faculty members. They have the greatest say in the library resource purchase. Besides, a set of reasonable decision-making procedures should be put in place, and a resource purchase evaluation group should be set up to comprehensively evaluate the purchase project. The purchase should be conducted according to the evaluation marks. In the purchase link, university and college libraries should standardize the purchase process and reduce various forms of corruption by inviting bidders extensively $^{[4]}$.

\section{Enhance resource-sharing}

In the Internet era, the cost of transmitting resources is very low, various universities and colleges can enhance their resource-sharing. To any universities and colleges, their resource purchase budgeting is limited, and the resources they can purchase are also limited. Under the condition, it is a reasonable choice to enhance resource-sharing. University and college universities should make full use of inter-library loan to enhance their cooperation and connection. Through resource-sharing, they can, on the one hand, enrich the library resources; on the other hand, reduce the purchase cost. Of course, university and college libraries should find the proper cooperators and conduct resource-sharing in line with the basic principle of resource complementarity. In the advanced stage of resource-sharing, university and college libraries should 
deepen their cooperation. Each side should arrange the budgeting to their own situation so as to maximize the richness of library resources at the minimum cost.

\section{Improve the comprehensive qualities of librarians}

To improve the comprehensive qualities of librarians is the foundation for university and college library resource construction. The comprehensive qualities of librarians directly decide the quality of library resource construction. Therefore, in order to ensure the quality of university and college resource construction, it is necessary to take effective measures to improve the comprehensive qualities of librarians. On the one hand, attention should be paid to the introduction of relevant talents. With the popularity of various new techniques in university and college library resource construction, university and college libraries have higher requirements for employees' qualities and abilities. For example, in terms of document delivery, librarians should have relevant professional knowledge and skills. On the other hand, attention should be paid to the cultivation of librarians' abilities. Various forms of training should be adopted to improve librarians' abilities, update their professional knowledge and provide adequate human resources for the university and college library resource construction $^{[5]}$.

\section{CONCLUSIONS}

In view of the position and role of university and college scientific research and teaching, this paper thinks that the focus of university and college library construction should be on the library resources. In recent years, the number of university and college students keeps increasing and the construction conditions of university and college libraries keep improving, but the library resource construction witnesses no great strides, which cannot meet the requirements of increasing schooling scale and professional programs. Inadequate attention is paid to the digitalization, specialization, sharing and virtualization development trend of the library resources, thus resulting in backward university and college library construction. In the future, university and college libraries should keep on exploring, and make full use of the network and information techniques to enrich the library resources and ensure the full play of the functions of library resources in the teaching and scientific research activities.

\section{ACKNOWLEDGMENT}

This paper is the periodical achievement of the research project of "In-depth integration and recommendation of library resources under the big data background” (Project No.: 2015019) in 2015 of CALIS China Agriculture Literature and Information Center.

\section{REFERENCES}

Liu Shuyin. Exploring into the Collection Resources Construction of
University Library[J]. Value Engineering,2014(5):192-193.

[2] QiuJunping. Review of the Visualization Researches on Library-Collected Resources Abroad[J]. Information and Documentation Services,2014(1):12-19.

[3] Zhang Yufeng. The Visualization Framework of In-depth Aggregation $\mathrm{R}$ esults of Library $\mathrm{R}$ esources Under Semantic Environment[J]. Documentation, Information \& Knowledge,2014(5):65-71.

[4] Yao Liping. Probe into the Collection Resources Construction and Service Mode of University Library[J]. Sci-Tech Information Development \& Economy,2014(10):93-95.

[5] Hu Lin. Locating the Core Responsibility of Subject Librarian by Collection Development[J]. Library Journal,2011(3):50-52. 